\section{The Global Demand For United States Frozen Potatoes in the Year 2000}

\author{
Yanqing $\mathrm{Gao}^{1}$ and \\ Joseph F. Guenthner ${ }^{2}$
}

Additional index words. Solanum tuberosum, econometrics, food service, retail, exports, Japan

Summary. An econometric model was developed to forecast the global demand for U.S. frozen potato products in the year 2000. Quantity-dependent demand equations were established for the U.S. retail market, the U.S. food service market, the Japanese market, and the rest of the world. It was estimated that total sales of U.S. frozen potato products will be 81.5 million cwt in 2000, a 33\% increase from 1989. The domestic retail market is forecast to increase by $4 \%$, and the food service market by $33 \%$. Exports are expected to double 1989 volume, with a $30 \%$ increase in exports to Japan and a $264 \%$ growth in exports to the rest of the world.

$\mathrm{T}$ he potato market is changing and becoming increasingly complex. Several decades ago, the primary market for the U.S. potato industry was fresh potatoes prepared at home. Today, the frozen potato market is as large as the fresh potato market, and $85 \%$ of frozen potatoes are consumed away from home. The popularity of fast-food restaurants has fueled much of the increase in consumption of frozen french fries and other frozen potato products.

Another source of growth is the export market. Like in the United States, the fast-foodindustry has grown rapidly overseas. During the 1980s, the number of fast-food restaurants in Japan grew at annual rates ranging from $10 \%$ to $21 \%$ (Potato Board, 1990).

Department of Agricultural Economics and Rural Sociology, University of Idaho, Moscow, ID 83843

${ }^{1}$ Research Associate.

${ }^{2}$ Professor.
Many of these fast-food restaurants, including U.S. franchises such as McDonalds and Burger Ring, feature frozen french fries as an important menu item.

Something that has not changed in the potato industry is price volatility. Relatively small increases in supply have caused potato prices to decrease to levels well below costs of production. The main reason is the inelastic demand for potatoes that was discussed years ago by Gray et al. (1954), Simmons (1962), and Hee (1967), and confirmed by more recent research (Jones and Ward, 1989; Guenthner et al., 1991a, 1991b).

A concern in the potato industry is that production should not expand more rapidly than demand. To avoid this problem, an understanding of frozen potato demand is important. Therefore, an analysis of the global market for U.S. frozen potatoes was conducted. The specific objective was to forecast the demand for U.S. frozen potatoes in the year 2000 .

\section{Methods}

Mar\&\&s. The market for U.S. frozen potato products was divided into four segments: 1) the domestic retail market, 2) the domestic food service market, 3) Japan, and 4) the rest of the world (ROW). In 1990, the domestic retail market accounted for $\approx 13 \%$ of sales, the domestic food service market $80 \%$, the Japanese market $5 \%$, and ROW 2\% (National Potato Council, 1991).

Explanatory variables. According to economic theory, there are four things that can shift the demand for a product: 1) population; 2) consumer income; 3) prices of other goods; and 4) tastes and preferences (Tomek and Robinson, 1990). Explanatory variables representing the four demand shifters were used to estimate demand equations in this study.

The population demand shifter was incorporated into the models by dividing frozen potato quantities and consumer income by population. Percapita consumption of frozen potatoes was the dependent variable in each equation. Per-capita income was an explanatory variable representing two of the four demand shifters. The sign of the income coefficient was expected to be positive, indicating that consumers purchase more frozen potatoes as their income rises. 
The price-of-other-goods demand shifter was included in the domestic equations by including both a substitute and a complement. The substitute was fresh potatoes. As fresh potato prices increase, consumers would be expected to substitute frozen for fresh potatoes. The sign of the coefficient was expected to be positive. Hamburger price was included in the domestic equations to represent a complement. Since many consumers eat hamburgers and french fries together, an increase in the price of hamburger was expected to have a negative impact on demand for frozen potatoes. To capture the influence of the prices of other goods and services, all monetary variables were deflated by the consumer price index.

The tastes-and-preferences demand shifter was represented by four types of variables. The percentage of females in the labor force was used to capture a preference for convenience. It was assumed that, as more women work outside the home, they would have less time to prepare meals and would prefer more convenience in their foods. Because processed potatoes are more convenient to prepare than fresh potatoes, the expected sign of the variable was positive.

The percentage of homes that own microwave ovens is another tastesand-preferences variable. Microwave ovens have made it more convenient to bake fresh potatoes. Guenthner et al. (1991a) found that microwave oven ownership increased the demand for fresh potatoes at the expense of frozen potatoes. The expected sign of this variable was negative.

Advertising is designed to shift consumer tastes and preferences. Two types of advertising variables were included in the domestic models. One was brand advertising expenditures by frozen potato processors. The other was generic advertising expenditures by the $\mathrm{N}$ ational Potato Board and state potato commissions. This type of advertising was called generic because it is for potatoesin general rather than for a particular brand or type of product. The expected sign of both variables was positive.

The fourth type of tastes-andpreferences variable was a dummy variable representing the quarter, or season of the year. It was hypothesized that consumer demand for frozen potato products may be different during different times of the year. Due to data limitations, this variable could be included only in the domestic retail market.

Data considerations. The U.S. Department of Agriculture does not provide frozen potato data segmented into retail and food service sectors. To study the two markets separately, U.S. retail frozen potato price and quantity data were purchased from Nielsen Marketing Research, Inc., (Chicago). Food service consumption data were estimated by subtracting retail consumption from total consumption, which were provided by USDA (Putnam and Allshouse, 1991). Because the USDA data were only available on an annual basis, a quarterly model for the food service market could not be developed.

Generic and frozen potato advertising data were purchased from Leading National Advertisers, Inc. (New York). The data consisted of quarterly advertising expenditures for potatoes through six media-magazine, newspaper supplements, network television, spot television, network radio, and outdoor. Using aggregate advertising data assumes that consumers have the same response to advertisement expenditures regardless of how it is spent. Generic advertising included expenditures by the National Potato Promotion Board, Idaho Potato Commission, Washington State Potato Commission, Maine Potato Board, Michigan Potato Commission, and other state potato associations. Frozen potato advertising included brand advertising expenditures by Carnation, OreIda, Simplot, and other potato processors.

Other data used in the domestic models were obtained from federal government sources. The U.S. Department of Labor (USDL) was the source for data on the consumer price index, the price index of fresh potatoes, the price index of hamburger meat, and the female labor participation rate. U.S. Dept. of Commerce (USDC) publications provided data on population, disposable consumer income, and the percentage of households with microwave ovens.

For the export markets, the main source of data was USDA Foreign Agricultural Service (FAS), which provided export quantities and values to Japan and the rest of the world. Japanese population and gross domestic product were obtained from the International Monetary Fund (IMF). Japan's consumer price index and the exchange rate of Japanese yen with U.S. dollars were obtained from the USDC.

The combination of public and private data sources could not provide all the data. Due to data limitations, the income variable for the Japanese market is per-capita gross domestic product (GDP) rather than per-capita disposable income, which was used for the U.S. domestic market. Also, price data for frozen potatoes in the U.S. food service market were not available, which makes the specification of food service demand different from retail demand. This problem has been wellexplored in a previous study by Guenthner et al. (1991 b).

The data set is limited to the period of 1970 to 1989 for the U.S. domestic market, and 1978 to 1990 for the international market. Quarterly data were used for the U.S. retail market and the Japanese market, while annual data were used for the U.S. food service market and the rest of the world.

Estimation methods. Demand equations for the domestic markets and the Japanese market were estimated via ordinary least squares (OLS) or generalized least squares (GLS). Econometric results were analyzed as suggested by Judge et al. (1988). The Durbin-Watson statistic was used to detect serial correlation problems. The Glejser test was used to check for heteroskedasticity. Correlation between explanatory variables was used to detect multicolinearity problems.

The ROW demand was modeled as a simple linear function of time. Because there are many countries included in ROW, developing explanatory variables to represent the four demand shifters was not feasible.

\section{Results}

The U.S. retail market. The equation for the U.S. retail market shows that all coefficients have the anticipated signs (Table 1). Demand for frozen potatoes increases as prices for frozen potato products fall. Increased consumer income increases demand. When the price ofhamburger increases, demand for frozen potatoes declines. When fresh potato prices increase, demand for frozen products will increase. 
Table 1. Estimated equations for U.S. frozen potato demand.

\begin{tabular}{|c|c|c|c|c|}
\hline $\begin{array}{l}\text { Explanatory } \\
\text { variables }\end{array}$ & $\begin{array}{c}\text { Domestic retail } \\
\text { (lb/capita) }\end{array}$ & $\begin{array}{c}\text { Domestic food } \\
\text { service (lb/capita) }\end{array}$ & $\begin{array}{c}\text { Japanese market } \\
\text { (lb/capita) }\end{array}$ & $\begin{array}{c}\text { Rest of world }{ }^{x} \\
(1000 \mathrm{t})\end{array}$ \\
\hline Constant & $0.48(3.3)^{y}$ & $-18.49(-3.2)$ & $-0.73(-4.5)$ & $-5.494(-6.0)$ \\
\hline Year & & & & $12.3(6.0)$ \\
\hline Retail price & $-0.67(-4.9)$ & & & \\
\hline Export price & & & $-0.26(-1.6)$ & \\
\hline Consumer income & $0.005(2.4)$ & $4.50(7.2)$ & $0.50(11.0)$ & \\
\hline Price-hamburger & $-0.068(-1.8)$ & $-9.38(-4.9)$ & & \\
\hline Price-fresh potatoes & $0.14(6.1)$ & $1.73(1.1)$ & & \\
\hline Females in labor force & $0.007(1.8)$ & & & \\
\hline Microwave ovens & $-0.003(-6.2)$ & $-0.13(-5.0)$ & & \\
\hline Advertising-frozen & $3.09(3.9)$ & & & \\
\hline Advertising-generic & & $172.5(3.3)$ & & \\
\hline Winter $(\mathrm{Ql})$ & $0.09(11.8)$ & & & \\
\hline Spring (Q2) & $0.053(5.1)$ & & & \\
\hline Summer (Q3) & $-0.028(-2.5)$ & & & \\
\hline Exchange rate & & & $0.0003(-1.9)$ & \\
\hline$R^{2}$ & 0.84 & 0.94 & 0.96 & 0.90 \\
\hline
\end{tabular}

Data for 1985-89.

${ }^{y}$ Values in parentheses are $\mathrm{t}$ values.

The female labor force participation rate has a positive impact on demand. The growing proportion of women in the labor force results in less time for food preparation. Because women prepare more meals than men in most households, convenient-toprepare frozen potato products are in higher demand when more women are in the labor force.

The percentage of households using microwave ovens has a negative impact. One reason is that many consumers may not have been aware of microwaveable frozen potato products. Another reason may be poor quality of microwaveable frozen potato products. The crispness that consumers expect in french fries is difficult to produce in the microwave (Valentino, 1988). As a result, consumers tend to substitute fresh potatoes for the frozen products once they purchase microwave ovens.

Brand advertising by frozen potato processors is apparently effective in stimulating demand in the retail market. While generic advertising focuses on stimulating the total demand for potatoes, individual processors may be more interested in increasing their market share than increasing the total market demand. Therefore, the actual effects of brand advertising for individual potato processors can be even greater than this study indicates.

There is seasonality in the consumption pattern of frozen potatoes in the U.S. retail market. Sales of frozen potato products are highest in the (Fig. 1).
Variables that affect the food service market are similar to those that affect the retail market (Table 1). Consumer income has a significant positive impact on away-from-home frozen potato consumption. Increased income enables consumers to expand their purchases of food away from home, boosting sales of frozen potatoes in the food service market.

The price of hamburger has a negative effect on the demand for frozen potatoes because these two products are complementary. The positive coefficient for fresh potatoes indicates that they compete with frozen products in both the retail and food service markets. When the price of fresh potatoes falls, the demand for frozen potatoes is reduced as consumers substitute fresh for the frozen products athome as well as away from home.

As in the retail market, the percentage of households using microwave ovens shows a negative effect on demand for frozen potato products in the food service market. If consumers eat more fresh potatoes prepared in microwave ovens at home, they are likely to consume less frozen potatoes in the food service market.

Frozen potato demand in the food service market responds positively to generic advertising. Advertising expenditures on frozen potatoes, however, do not seem to have a significant impact on the consumption in the food service market. Brand advertising is probably not as effective on institu-

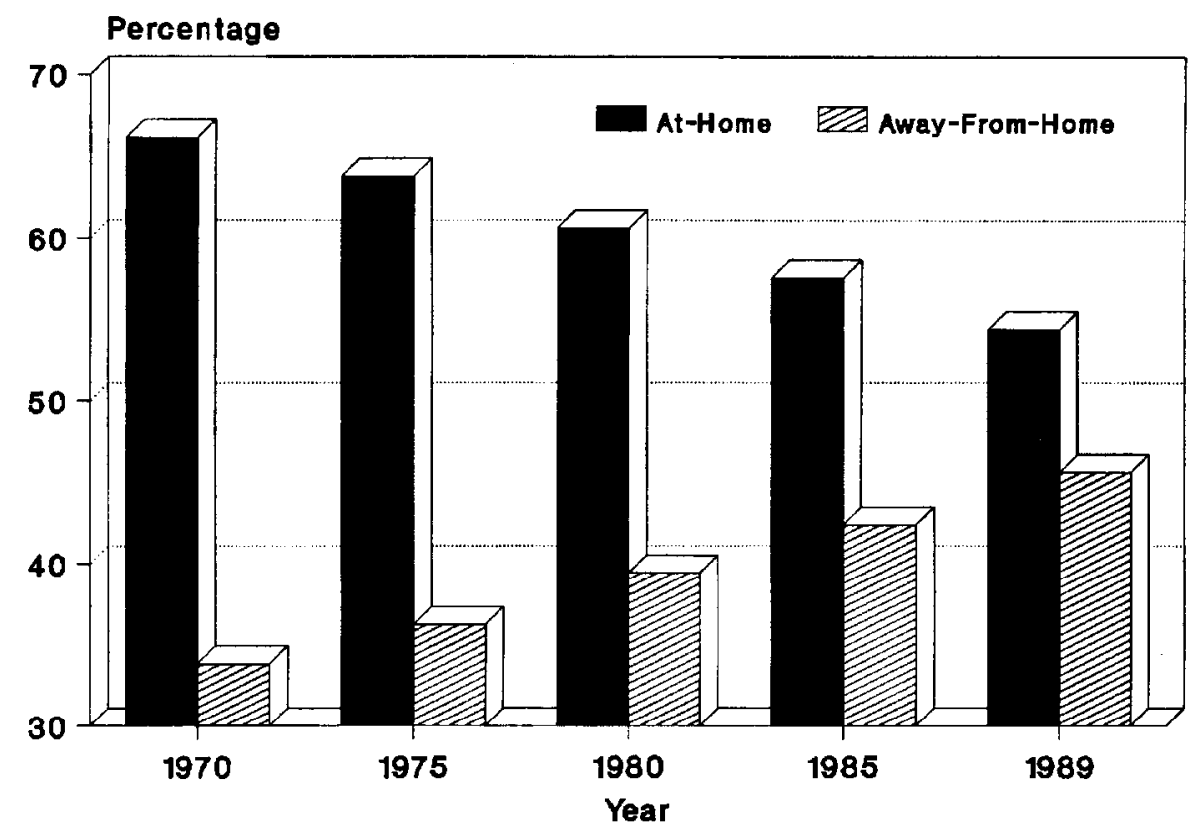

Fig. 1. U.S. food sales-at-home and away from home. Source: USDA. 


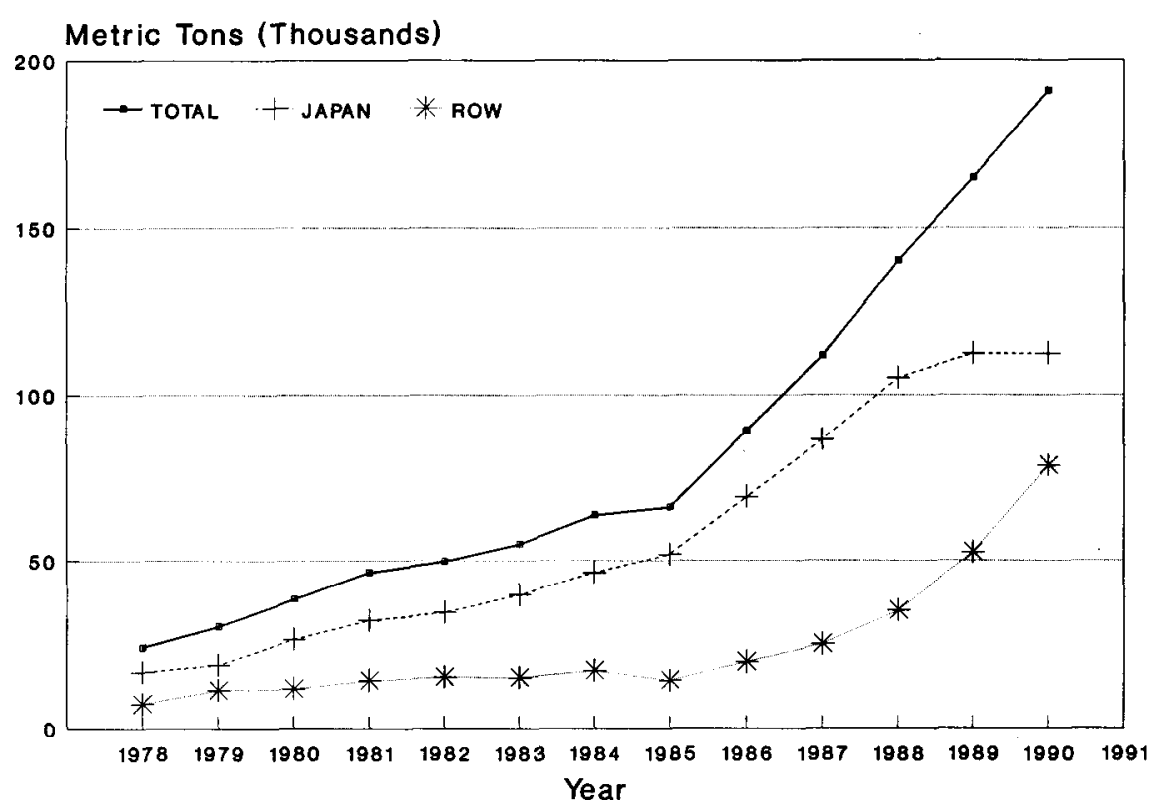

Fig. 2. U.S. frozen potato exports. Source: USDA.

tional buyers as it is on final consumers as in the retail market.

The Japanese market. Growth in frozen potato consumption is evident not only in the U.S. market but in export markets as well. U.S. frozen potato exports grew 693\%, from 24,085 tin 1978 to 190,948 tin 1990 (Fig. 2). The driving force behind this significant increase is Japan. Japan is a highly industrialized and densely populated country that has been the largest single-country foreign market for U.S. agricultural export since 1963. The United States has been taking an increasingly larger share in the Japanese frozen potato market, up from $28.5 \%$ to $72 \%$ in 1988 , and was estimated to be close to $80 \%$ in 1991 (Squires,1986).

Japan's booming economy and high per-capita income have had significant impacts on demand for U.S. frozen potatoes (Table 1). Strong economic growth gives the Japanese people an increasing exposure to western foods and lifestyle. The high percapita income allows them to buy more service-added products that offer convenience rather than the raw products that require a lot of preparation.

The currency exchange rate, expressed as yen per dollar, has a negative effect on the frozen potato consumption. When the dollar depreciates against the yen, the effective price of frozen potatoes becomes cheaper for Japanese importers. This causes them to increase imports from the United States, perhaps at the expense of competing exporters.

Table 2. Top $\mathbf{1 0}$ markets for U.S. frozen potato exports."

U.S. Dept. of Agriculture (1990). sion of U.S. frozen potato exports to these Asian Pacific Rim nations is attributed to their booming economies, import liberalization, exchange rate fluctuations, a general trend toward western lifestyle and foods, growing tourism, and increasing promotion efforts made by the potato industry.

Japan is the well-developed firsttier market for frozen potato exports, and the Four Little Dragons make up the second tier. The third tier consists of other A sian Pacific Kim nations that are not yet significant in terms of trade volume, but that have grown rapidly in recent years. These countries include the Philippines, Malaysia, Indonesia, Thailand, and the People's Republic of China. They have potential for future development similar to the Four Little Dragons.

To assess the demand from the rest of the world, which takes a small market share and includes numerous countries, trend analysis was done rather than attempting to establish an econometric model for each country. Figure 2 indicates a turning point of U.S. frozen potato exports to the rest of the world in 1985. This is the year the dollar reached its peak and started to depreciate against the currencies of major trading partners, including Japan. The devaluation of the dollar lowered the price of U.S. food products and sharpened the competitive edge of frozen potato exports in the world market in the years that followed. In addition, the emergence of Asia as the dominant regional market for U.S. agricultural products further stimulated the exports of frozen potatoes in the late 1980s.

To capture more accurately the

\begin{tabular}{lrrrrr}
\hline & \multicolumn{2}{c}{ Quantity (t) } & & Percent, 1989 & Change, 1980-89 \\
\cline { 2 - 3 } Country & 1980 & $\mathbf{1 9 8 5}$ & & 112,252 & 323 \\
Japan & 26,546 & 51,925 & & 477 \\
Hong Kong & 2,590 & 4,011 & 14,937 & 699 \\
Singapore & 895 & 2,636 & 7,150 & \\
Taiwan & 0 & 74 & 5,916 & 819 \\
Bahamas & 481 & 111 & 4,422 & 1898 \\
Malaysia & 199 & 1,007 & 3,976 & 21 \\
Canada & 2,284 & 3,782 & 2,774 & 2,464 \\
South Korea & 108 & 599 & 2,769 & 10,272 \\
Philippines & 25 & 0 & 2,593 & 396 \\
Indonesia & 249 & 284 & 1,235 & 36 \\
Rest of world & 4,972 & 1,718 & 6,774 & 330 \\
Total & 38,349 & 66,147 & 164,798 & \\
\hline
\end{tabular}


trend of the demand from the rest of the world, the data set was divided into two parts: 1978-1984 and 19851990. Two separate regressions were run for the two periods, improving statistical results. The recent trend line from 1985 to 1989 is used in this study to project the demand from the rest of the world in the year 2000. It should be noted that structural changes in the future could alter the slope of the 1985-90 trend line.

Statistical tests. Equationswere tested for problems with serial correlation, heteroskedasticity and multicolinearity. A serial correlation problem in the retail equation was solved by transforming the variables using a modified Cochrane-Orcutt method (Judgeetal., 1988).A Durbin-Watson statistic of 2.11 for the generalized least squares (GLS) model indicates that the serial correlation problem was solved.

Multicolinearity was present in both the retail and food service equations. Female labor force participation rate and the percentage of households using microwave ovens are highly correlated with per-capita disposable income. This, however, will not affect the usefulness of the model for making accurate forecasts outside the sample if the interrelationships among the explanatory variables follow the same pattern in the forecast period as in the sample period (Koutsoyiannis, 1977). Because the goal was to forecast demand in 2000, and the interrelationships among the variables that affect the demand for frozen potatoes in the sample period are likely to continue into the future, remedial action was not taken.

In the equation for Japan, a weighted least squares (WLS) equation based on transformed data was tested to alleviate problems with serial correlation and heteroskedasticity. However, the $R^{2}$ was reduced from 0.96 in the OLS model to 0.39 in the WLS mode. Because a high $R^{2}$ is generally accepted as a more-important criterion than low standard errors in forecasting (Koutsoyiannis, 1977), the OLS model was adopted despite the presence of heteroskedasticity.

Forecasts of explanatory variables. Forecast values for the explanatory variables in the year 2000 were needed to forecast frozen potato demand. These forecasts were obtained from the following methods, in order of preference: 1) government forecasts, 2) functions of time, and 3) average value or last observation.

Forecasts of U.S. population and female labor force participation rate in 2000 are provided in the USDC Statistical Abstract of the United States (1991). Japanese population projections were provided in the Japanese Bureau of Statistics Japan Statistical Yearbook (1991). Government estimates for other explanatory variables were not found.

Income, consumer price index, price of frozen potatoes, fresh potato price index, and hamburger price index were estimated from simple linear trends. The statistical results indicated a satisfactory goodness of fit $\left(R^{2}>\right.$ 0.75) for all these trend models.

The microwave oven variable graphically shows a marked S-shaped growth pattern, and was estimated by using the logistic growth function $\mathrm{P}_{\mathrm{t}}=$ $K /\left[1+\mathrm{e}^{-(\mathrm{a}+\mathrm{bt})}\right]$, where $P_{t}$ is the percentage of households that use microwave ovens in year $t ; k$ is the ceiling value, which is set at $98 \%$; $t$ is the time variable; $a$ is a constant that positions the data curve on the time scale; and $b$ is the rate of growth coefficient. The statistical results showed a very good fit $\left(R^{2}=0.99\right)$.

For three explanatory variables, generic advertising, brand advertising, and currency exchange rate, time analysis did not provide a satisfactory forecasting tool. Therefore, average 197089 deflated values of advertising ex- penditures (both generic and frozen) were used as the year 2000 estimates. Because yen/ dollar exchange rates are influenced by many economic factors and are difficult to forecast, the exchange rates for 2000 are assumed to be the same as in 1990.

Year 2000 forecast. It is estimated that the total demand for U.S. frozen potato products will reach 81.5 million cwt at the forecast price level in year 2000, a 33\% increase from 1989 (Fig. 3). The domestic retail market is forecast to increase 4\%, up from 9.71 million cwt in 1989 to 10.1 million cwt in 2000. The food service market is expected to expand $33 \%$, from 47.98 million cwt in 1989 to 64.02 million cwt in 2000.

The export market is expected to double its 1989 size by year 2000. Exports of U.S. frozen potato products to Japan are projected to increase to 3.2 million cwt in year 2000 , a $30 \%$ growth above the 2.47 million cwt in 1989. Exports of frozen potatoes to the rest of the world are forecast to grow $264 \%$, from 1.16 million cwt in 1989 to 4.22 million cwt in 2000.

This study projects that, by the year 2000, the foreign market will account for $9 \%$ of total demand for U.S. frozen potatoes, compared to $7 \%$ in 1990. Clearly, the U.S. frozen potato market will continue to be dominated by domestic consumption, especially in the food service market, even though foreign demand will grow faster than domestic demand (Fig. 4).

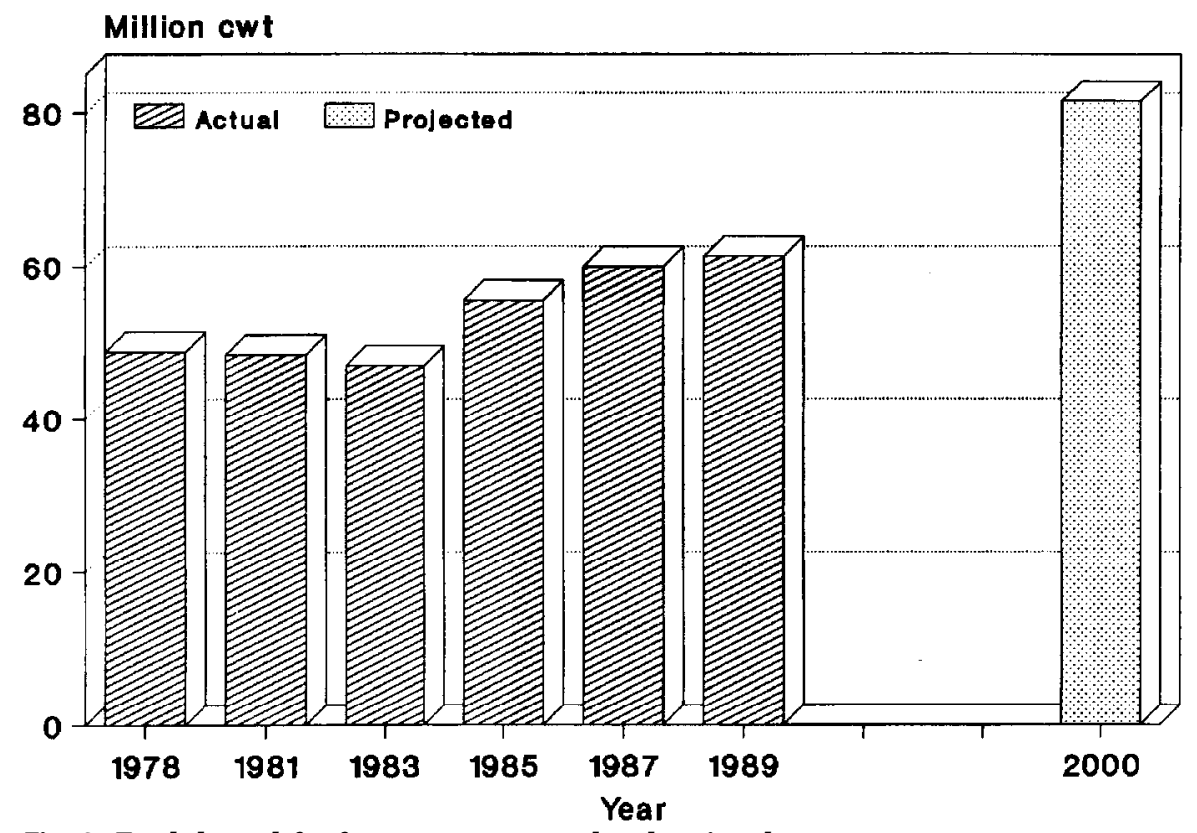

Fig. 3. Total demand for frozen potatoes-actual and projected. 


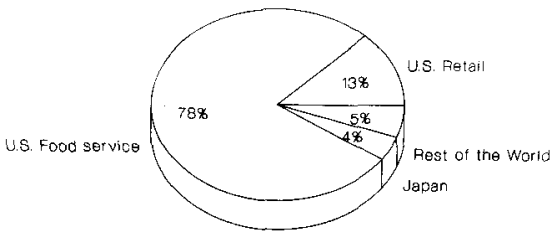

Fig. 4. Projected market share year 2000.

\section{Discussion}

Price, income, andcross-price elasticities were estimated to provide additional demand analysis information (Table 3). The own-price elasticity confirms that the demand for frozen potatoes is inelastic in both the U.S. and Japanese markets. The high income elasticity in the Japanese market and the U.S. food service market suggests that economic growth can boost the demand for frozen potato products.

Sensitivity analysis was conducted on the three variables for which the least desirable projection methods were used. The change from the baseline forecast for the lowest and highest observations of the variables were: frozen brand advertising, $-2.6 \%$ and $+2.9 \%$ changes in U.S. retail demand; generic advertising, $-6.5 \%$ and $+5.5 \%$ changes in U.S. food service demand; and exchange rate, $-6.6 \%$ and $0.3 \%$ changes in Japanese demand. More reliable estimates of these variables could improve forecast accuracy, but not by a large amount in terms of total frozen potato demand.

Other factors that could have an impact on the demand for U.S. frozen potatoes were not included in the econometric models because of statistical problems and/or data availability problems. Among the variables that were hypothesized to be important, but not included, were: household size, age composition of the population, advertising expenditures for dehydrated potatoes, targeted export assistance (TEA) expenditures, number

Table 3. Price, income, and cross-price elasticities, estimated at mean values.

\begin{tabular}{|c|c|c|c|}
\hline Variable & $\begin{array}{c}\begin{array}{c}\text { Domestic } \\
\text { retail }\end{array} \\
\end{array}$ & $\begin{array}{l}\text { Domestic } \\
\text { food service }\end{array}$ & $\begin{aligned} & \text { Japanese } \\
& \text { e market } \\
&\end{aligned}$ \\
\hline Own-price & -0.49 & & -0.23 \\
\hline Income & 0.56 & 2.80 & 3.40 \\
\hline $\begin{array}{l}\text { Cross-price- } \\
\text { hamburger }\end{array}$ & -0.08 & -0.66 & \\
\hline $\begin{array}{l}\text { Cross-price- } \\
\text { fresh potatoes }\end{array}$ & 0.16 & 0.12 & \\
\hline
\end{tabular}

of western-style restaurants in Japan, and the number of Japanese people traveling abroad. If data and statistical problems are solved, further studies can be conducted on the relationship between demand for frozen potatoes and some of these variables.

The microwave oven variable has negative coefficients in both the U.S. retail and food service markets. Product development, advertising, and education may help change the situation in the future. If the industry develops new frozen potato products, or improves the quality of microwaveable french fries, the microwave oven varable might have a positive impact on frozen potato demand. Consequently, domestic demand could grow faster than forecast.

Beside new products, new markets for U.S. frozen potatoes are emerging as the worldwide economic situation changes. Many markets other than Japan warrant closer observation and detailed study. The Four Little Dragons clearly merit further market development. The third-tier markets also will present future opportunities to the frozen potato industry.

The U.S. frozen potato industry will be involved increasingly in global markets. Exports will grow more rapidly, in percentage terms, than the domestic market. The domestic market, however, will continue to dominate in the year 2000 and beyond. The total market for U.S. frozen potatoes is expected to grow $\approx 3 \%$ per year. If frozen potato supply grows more rapidly than demand, prices will decline.

\section{Acknowledgement}

We acknowledge the Univ. of Idaho College of Agriculture and the Idaho Potato Commission for their support of this research.

\section{Literature Cited}

Gray, R.W., V.L. Sorenson, and W.W. Cochrane. 1954. An economic analysis of the impact of government programs on the potato industry in the United States. Minnesota Agr. Exp. Sea. Bul. 211.

Guenther, J.F., B.-H. Lin, and A.E. Levi. 1991a. The influence of microwave ovens on the demand for fresh and frozen potatoes. J. Food Distr. Res. 23(3).

Guenther, J.F., B.-H. Lin, and A.E. Levi. $1991 b$. Factors that affect the demand for potato products in the United States. Amer. Potato J. 68(9).
Hee, O. 1967. Demand and price analysis for potatoes. USDA Tech. Bul. 1380.

International Monetary Fund. 1978-1991. International financial statistics. IMF, Washington, D.C.

Japan Bureau of Statistics. 1978-1991. Japan statistical yearbook. Sorifu, Tokeikyoku, Japan.

Jones, E. and R.W. Ward. 1989. Effectiveness of generic and brand advertising of fresh and processed potato products. Agribusiness 5(5).

Judge, G.G., R.C. Hill, W.E. Griffith. 1988. Introduction to the theory and practice of econometrics. Wiley, New York.

Koutsoyiannis, A. 1977. Theory of econometrics. Harper \& Row, New York.

Market Makers, Inc. 1988. The Japanese food service market.

National Potato Council. 1991. Potato statistical yearbook.

Pendlum, D. 1990. U.S. agricultural trade: the decade in review. AgExporter, Mar. p 10-12.

Potato Board. 1990. Targeted export assistance plan.

Putnam, J.J. and J.E. Allshouse. 1991. Food consumption, price and expenditures, 196889. USDA Stat. Bul. 825 .

Simmons, W.M. 1962. An economic study of the U.S. potato industry. USDA Econ. Rpt. 6.

Squires, S. 1986. Humble potato becomes good-meal ambassador to Japan. Foreign Agr., Aug. p 14-15.

Tomek, W. G and K.L. Robinson. 1990. Agrcultural product prices. 3rd ed. Cornell Univ. Press, Ithaca, N.Y.

U.S. Department of Agriculture. 1990. U.S. frozen potato product exports. Horticultural products review. USDA, Washington, D.C.

U.S. Department of Agriculture. 1970-1991. Foreign agricultural trade of the United States. USDA, Washington, D.C.

U.S. Department of Commerce, Bureau of the Census. 1991. Statistical abstract of the United States. USDC, Washington, D.C.

U.S. Department of Commerce, Bureau of Economic Analysis. 1991. Business condition digest. USDC, Washington, D.C.

U.S. Department of Commerce, Bureau of Economic Analysis. 1970-1991. Survey of current business., USDC, Washington, D.C.

U.S. Department of Labor, Bureau of Labor Statistics. 1970-1991. CPI detailed report. USDL, Washington, D.C.

U.S. Department of Labor, Bureau of Labor Statistics. 1970-91. Monthly labor review., USDL, Washington, D.C.

Valentine, C. 1988. Growing up with microwaves. Supermarket News 38( 18). 